\title{
A synopsis of records of myxozoan parasites (Cnidaria: Myxozoa) from shrews, with additional data on Soricimyxum fegati from common shrew Sorex araneus in Hungary and pygmy shrew Sorex minutus in Slovakia
}

\author{
Csaba Székely ${ }^{1}$, Stephen D. Atkinson ${ }^{2}$, Kálmán Molnár ${ }^{1}$, László Egyed $^{1}$, András Gubányi ${ }^{3}$ and Gábor Cech ${ }^{1}$ \\ ${ }^{1}$ Institute for Veterinary Medical Research, Centre for Agricultural Research, Hungarian Academy of Sciences, Budapest, Hungary; \\ ${ }^{2}$ Department of Microbiology, Oregon State University, Corvallis, Oregon, USA; \\ ${ }^{3}$ Department of Zoology, Hungarian Natural History Museum, Budapest
}

\begin{abstract}
Myxozoans (Cnidaria: Myxozoa) are almost exclusively endoparasites of aquatic vertebrates and invertebrates, with the notable exception being two species of Soricimyxum Prunescu, Prunescu, Pucek et Lom, 2007 described from terrestrial shrews (Soricidae) in central Europe. Myxospores of the two parasites are morphologically indistinguishable, but have SSU rDNA sequences that differ by about $4 \%$. Herein, we report additional molecular and histology data from Soricimyxum fegati Prunescu, Prunescu, Pucek et Lom, 2007 from common shrew (Sorex araneus Linnaeus) from Hungary, and add a new geographic record for S. fegati in pygmy shrew (Sorex minutus Linnaeus) from Slovakia. A limited survey of shrews from the northern United States, Blarina brevicauda Say and Sorex sp. from New York, and Sorex spp. from Oregon, did not discover any infections, which is in stark contrast to the relatively high infection rates (up to 66\%) in European shrew populations. We also provide a summary and discussion of literature records of species of Soricimyxum and a host survey. Given the lack of distinguishing morphological or morphometric characters between Soricimyxum spp., and the overlap in vertebrate hosts and geographic ranges, unambiguous identification of these closely related shrew parasites can presently only be achieved through sequence comparison of one or more variable SSU rDNA regions.
\end{abstract}

Keywords: Eurasian shrew, Eurasian pygmy shrew, myxozoan infection, bile ducts, liver, mammal hosts, Central Europe

Myxozoans are cosmopolitan parasites of aquatic vertebrates, primarily fishes, with more than 2200 described species (Okamura et al. 2015). In the last ten years, two myxozoan species have been described from terrestrial mammals, specifically, three species of shrews in central Europe (Table 1). Soricimyxum fegati Prunescu, Prunescu, Pucek et Lom, 2007 and Soricimyxum minuti Székely, Cech, Atkinson, Molnár, Egyed et Gubányi, 2015 were described from bile ducts of Sorex araneus Linnaeus and Sorex minutus Linnaeus, respectively. Shrews infected with the same parasite species have been identified from localities more than $1000 \mathrm{~km}$ apart, at high infection prevalence up to $66 \%$, in mixed populations of Sorex spp. (Table 1, Fig. 1).

Dyková et al. (2007) redescribed S. fegati and showed by a study of the type material that the spore dimensions reported in the original description by Prunescu et al. (2007) are erroneously small. Dyková et al. $(2007,2011)$ also described the same myxozoan from three species of shrews in the southern Czech Republic and show genetic variation in the parasite SSU rDNA sequences (up to 4\%; Table 2).
A subsequent finding by Székely et al. (2015) of a genetically but not morphologically distinct myxozoan, S. minu$t i$, in pygmy shrews, demonstrated that DNA sequencing is necessary to distinguish between the two parasites.

In the present study, we sequenced additional shrew myxozoans from our earlier collections (Székely et al. 2015). We also surveyed additional shrews from localities in northwestern Hungary as part of the National Biodiversity Monitoring Program (Table 1). We extended the geographic range of samples to include shrews from southern Slovakia, which died during the Slovakian small mammal monitoring program in 2012. These samples were provided by Michal Ambros (Slovakian State Nature Conservation Centre, Nitra). To test the hypothesis that shrew myxozoans are common across the northern hemisphere, we also examined small mammals from East and West Coast localities in the United States (Table 1). Trap mortalities from shrew surveys in New York State were provided by Rick Ostfeld and Kelly Oggenfuss (Cary Institute of Ecosystem Studies). We undertook opportunistic sampling of natural mortalities in shrews and voles from Oregon, USA; some 
Table 1. Review of small mammals surveyed for myxozoan infections in central Europe and USA, showing collection locality and prevalence of infections. Type myxozoan records are in bold.

\begin{tabular}{|c|c|c|c|c|c|}
\hline Host species & Myxozoan & $\begin{array}{l}\text { Nos. infected/ } \\
\text { Nos. sampled } \\
\text { (prevalence) }\end{array}$ & Collection year & Collection locality & Reference \\
\hline Sorex araneus Linnaeus & $\begin{array}{l}\text { Soricimyxum fegati Prunescu, } \\
\text { Prunescu, Pucek et Lom, } 2007\end{array}$ & $19 / 46(41 \%)$ & 2001-2005 & $\begin{array}{l}\text { Poland, } \\
\text { Bialowieza primeval forest }\end{array}$ & Prunescu et al. 2007 \\
\hline Sorex araneus & S. fegati & $10 / 24(42 \%)$ & 2007 & \multirow{3}{*}{$\begin{array}{l}\text { Czech Republic, } \\
\text { Southern Bohemia }\end{array}$} & \multirow{3}{*}{ Dyková et al. 2007} \\
\hline Sorex minutus Linnaeus & S. fegati & $2 / 29(7 \%)$ & 2007 & & \\
\hline Neomys fodiens (Pennant) & - & $0 / 1$ & 2007 & & \\
\hline Sorex araneus & S. fegati & $51 / 98(52 \%)$ & $2007-2009$ & \multirow{3}{*}{$\begin{array}{l}\text { Czech Republic, } \\
\text { Southern Bohemia }\end{array}$} & \multirow{3}{*}{ Dyková et al. 2011} \\
\hline Sorex minutus & S. fegati ${ }^{\mathrm{a}}$ & $14 / 70(20 \%)$ & $2007-2009$ & & \\
\hline Crocidura suaveolens Pallas & S. fegati ${ }^{\mathrm{a}}$ & $1 / 10(10 \%)$ & $2007-2009$ & & \\
\hline Sorex araneus & S. fegati & $8 / 21(38 \%)$ & $2007-2010$ & \multirow[b]{2}{*}{ Hungary, Lipót } & \multirow[b]{2}{*}{ Székely et al. 2015} \\
\hline Sorex minutus & $\begin{array}{l}\text { Soricimyxum minuti Székely, } \\
\text { Cech, Atkinson, Molnár, } \\
\text { Egyed et Gubányi, } 2015\end{array}$ & $1 / 3(33 \%)$ & 2009 & & \\
\hline Sorex araneus & S. fegati & $2 / 3(67 \%)$ & 2011 & Hungary, Egervár & \multirow{6}{*}{ Present study } \\
\hline Sorex araneus & S. fegati & $1 / 8(13 \%)$ & 2010 & Hungary, Barbacsi Lake & \\
\hline Sorex minutus & S. fegati & $1 / 3(33 \%)$ & 2012 & Slovakia, Gbelce & \\
\hline Sorex minutus & - & $0 / 2$ & 2010 & Hungary, Barbacsi Lake & \\
\hline Sorex minutus & - & $0 / 1$ & 2011 & Hungary, Lipót & \\
\hline Neomys sp. & - & $0 / 5$ & 2011 & Hungary, Barbacsi Lake & \\
\hline Blarina brevicauda Say & - & $0 / 16$ & 2008-2010 & \multirow{2}{*}{ USA, Hudson River Valley, NY } & \multirow{4}{*}{ Present study ${ }^{\mathrm{b}}$} \\
\hline Sorex sp. & - & $0 / 23$ & 2010 & & \\
\hline Microtus canacaudis (Miller) & - & $0 / 6$ & 2011-2012 & \multirow{2}{*}{ USA, Corvallis area, Oregon } & \\
\hline Sorex sp. & - & $0 / 3$ & 2011-2012 & & \\
\hline
\end{tabular}

${ }^{\text {a }}$ PCR not specific for $S$. fegati, thus these infections could be either $S$. fegati or $S$. minuti (or a putative close relative); ${ }^{\text {b }}$ some of these USA data were reported as a personal communication in Hallett et al. (2015).

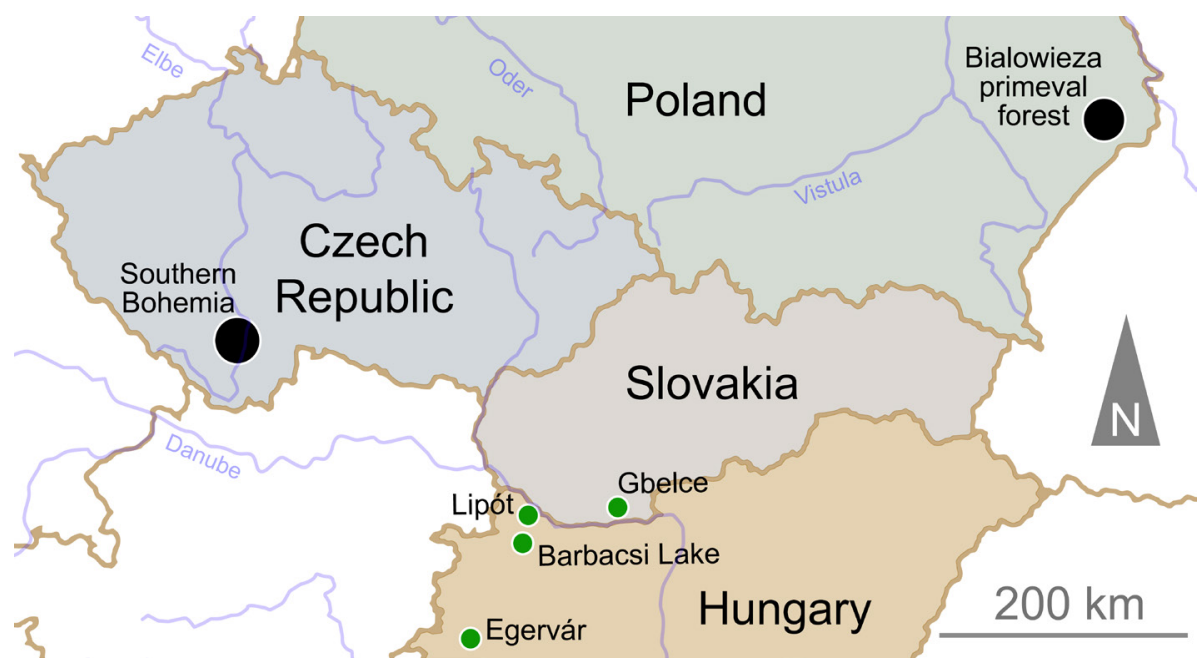

Fig. 1. Map showing localities in central Europe where infected shrews have been found. Locations from the present study are indicated in green.

of these data were included as a personal communication in Hallett et al. (2015), but are reported in full here for the first time.

Shrews were necropsied as reported previously (Székely et al. 2015). Briefly, we examined bile, gall bladder and liver as fresh squash preparations for the presence of myxozoan developmental stages and spores; animals from North America had been frozen prior to necropsy. Myxospores were photographed, measured and described per the guidelines of Lom and Arthur (1989). Liver tissue that included both mature spores and developmental stages was subdivided for histology and DNA extraction.
Survey results are shown in Tables 1 and 2. No infections were found in either the small number of Neomys sp. examined from Hungary, or in any of the North American shrews or voles. Infected species of Sorex were found in both northwestern Hungary and Slovakia. From a subset of visually positive shrews, parasite SSU rDNA was amplified and sequenced using PCR primers and cycling conditions reported previously (Székely et al. 2015). We designed one new Sorimyxum-specific primer SOR1050R (CCTCTCGCGCACAAATACC) to improve amplification of the 5' end of the target in semi-nested PCRs. Forward and reverse sequence segments were aligned by eye in 


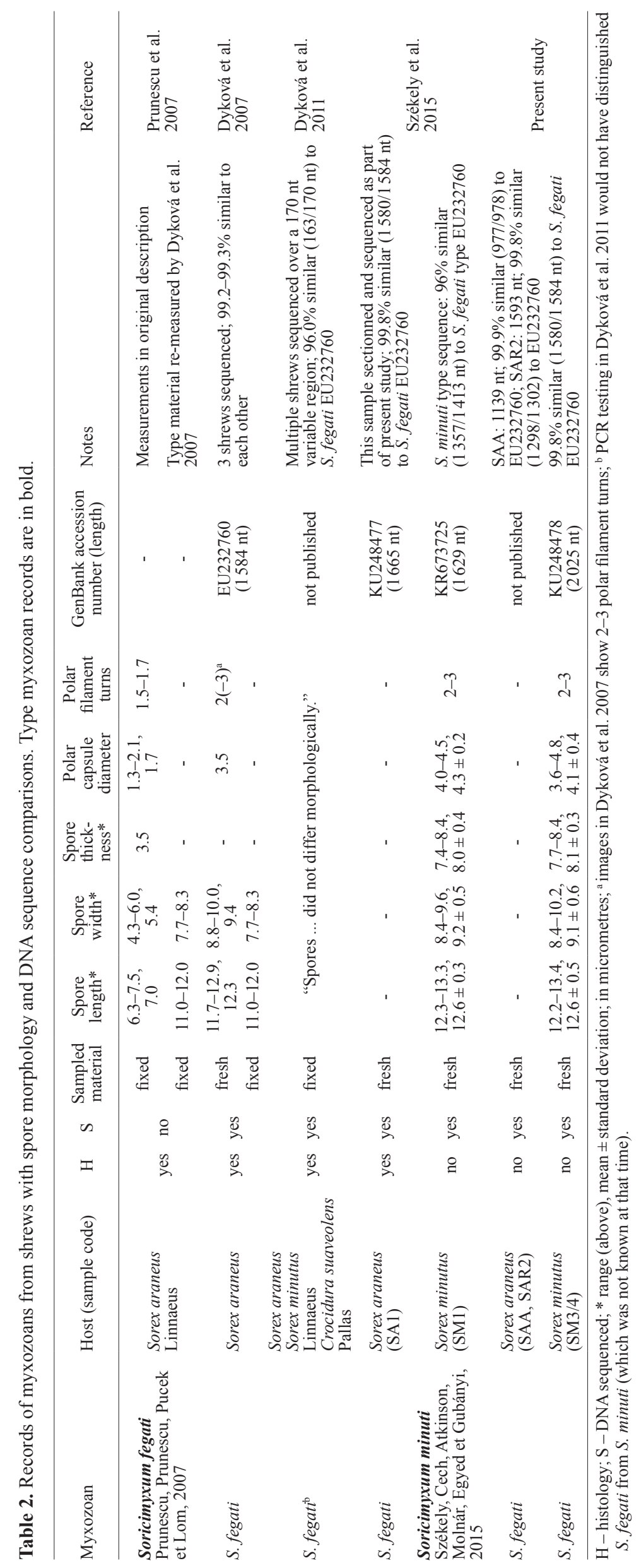



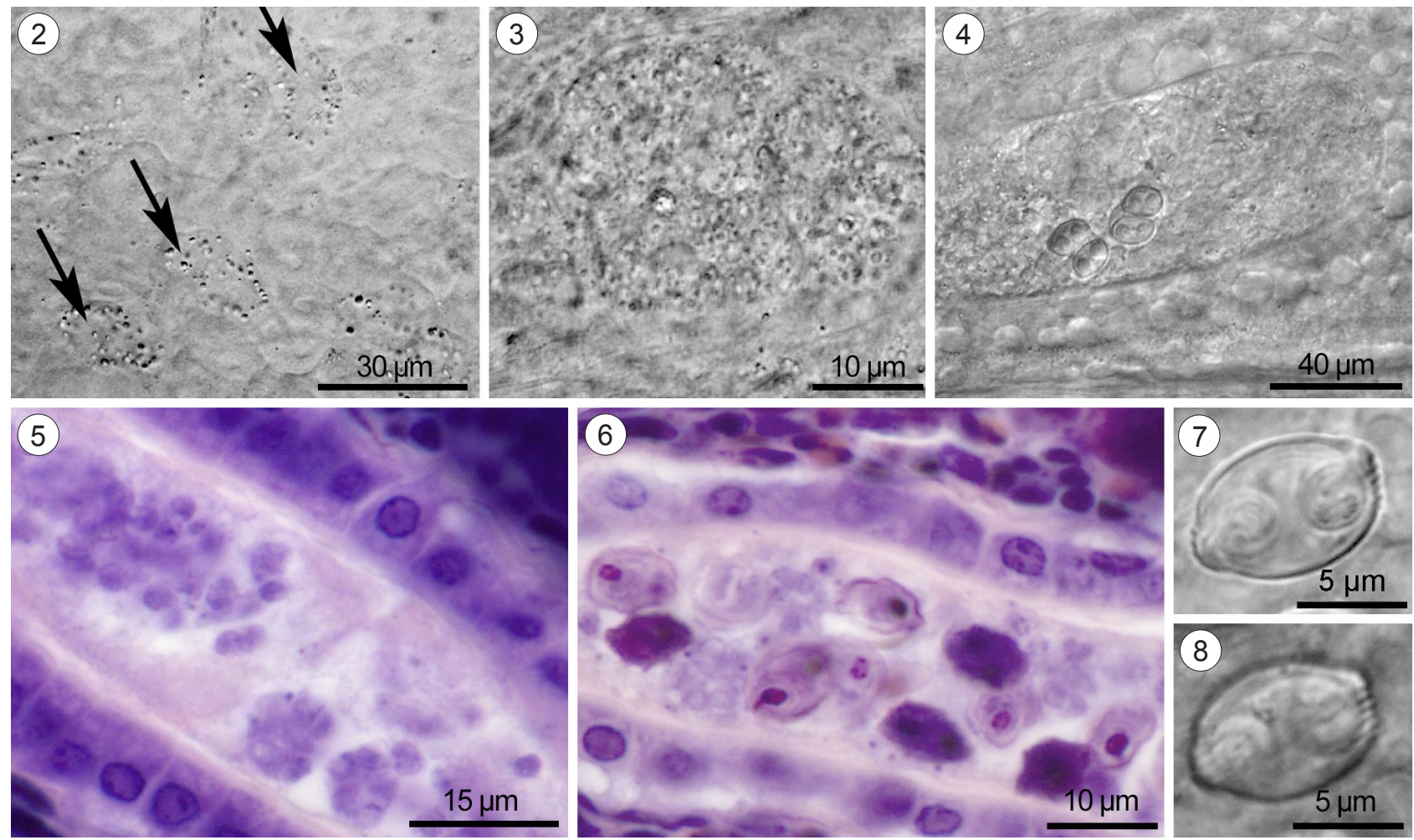

Fig. 2-8. Spores of Soricimyxum fegati Prunescu, Prunescu, Pucek et Lom, 2007 from the bile duct of the common shrew Sorex araneus Linnaeus from Hungary. Figs. 2, 3, 5. Early developmental stages (arrowed) in bile duct showing granular appearance and multiple nuclei. Figs. 4, 6. Sporogonic stages with developing plasmodium and mature myxospores from fresh (Fig. 4) and fixed material (Fig. $6 \mathrm{H \& E}$ ). Figs. 7, 8. Fresh, mature myxospore in sutural view in two different focal planes. Figs. 2-4. Phase contrast. Figs. 5, 6. Bright field. Figs. 7, 8. Nomarski interference contrast.

BioEdit (Hall 1999) and ambiguous bases clarified with reference to the corresponding ABI chromatograms. Sequence contigs were compared with reference sequences of species of Soricimyxum from NCBI GenBank (Table 2).

Despite the morphological indistinguishability of the two species of Soricimyxum, the DNA sequence data were unambiguous - we amplified only $S$. fegati from both $S$. araneus from Hungary and S. minutus from Slovakia. Sequence chromatograms did not show any evidence of mixed infections of $S$. fegati and S. minuti. The Slovakian infection was sequenced with primers ERIB1-SOR1050R, MYXGEN4F-ERIB10 to generate a near-complete SSU rDNA sequence, which was $99.8 \%$ similar with reference sequence of S. fegati EU232760. We also sequenced isolates from three infections of $S$. araneus from the northwestern Hungary (including one sample mentioned in Székely et al. 2015), SA1, sequenced with primers ERIB1SREV3, SFOR3-ERIB10. The parasite in all three of these S. araneus samples was $99.8-99.9 \%$ similar to the reference sequence of $S$. fegati.

Histological sections and digital images were deposited in the parasitological collection of the Zoological Department, Hungarian Natural History Museum, Budapest, collection numbers HNHM-18386 and HNHM-18387.

The earliest observed parasite stages in the bile ducts were oval or ramified, multinucleate, finely granular plasmodia $30-50 \mu \mathrm{m} \times 10-30 \mu \mathrm{m}$, which contained early sporogonic stages (Figs. 2, 3, 5). More advanced infections had 4 to 8 maturing spores in bisporic sporoblasts together with early sporogonic stages. (Figs. 4, 6). We did not observe any host reaction in the liver. Mature spores were slightly sigmoidal in sutural view (Figs. 7, 8), ellipsoidal in valvular view. Valves had a relatively thick suture running the length of the spore, and fine, longitudinal, surface ridges, parallel with the suture, distinctly visible in sutural view only (Fig. 8), with the greatest relief at ends of spore and very shallow to non-existent towards the middle of the spore. Two polar capsules, situated at the opposite ends of the spore, near-spherical, equal sized. Spore measurements are shown in Table 2 and are not significantly different from previous measurements of $S$. fegati or S. minuti. We could not identify any additional morphological characters to distinguish these two parasites.

Dyková et al. (2011) sequenced three short but relatively variable regions to assess infection status in three species of shrews (Table 1). Whereas the primers they designed distinguish between species of Soricimyxum and other myxozoan genera, we can now say that they are not specific enough to distinguish between $S$. fegati and S. minuti, which was discovered later. Hence, identification of $S$. fegati in the three shrew species by Dyková et al. (2011) may be ambiguous, particularly given that the variation they report (up to $4 \%$ in the $170 \mathrm{nt}$ variable region) is within the range expected of $S$. fegati and S. minuti; these sequences are not yet available in GenBank for comparison. In the current study, we have demonstrated conclu- 
sively that $S$. fegati can indeed infect both common shrew and pygmy shrew. Given the lack of distinguishing morphological or morphometric characters, and the overlap in vertebrate hosts and geographic range, unambiguous identification of these very closely related shrew parasites can only be achieved through sequencing of one or more regions that vary between these parasites, i.e. regions around SSU rDNA positions 490, 750, 970 and 1600.

The high prevalence of myxozoan infection in shrews. (typically 10-50\%) indicates that this parasite has been extraordinarily successful in adapting from purely aquatic ancestors to a terrestrial mode of existence. We suggest that future work should establish the range of infections in shrew populations outside of central Europe and extend surveys of shrews in North America, with an emphasis on aquatic shrew species: could those hosts have been a bridge for myxozoan parasites out of the aquatic environment? Or are semi-aquatic oligochaetes the 'bridg- ing host'? Life cycle of any of the species of Soricimyxum Prunescu, Prunescu, Pucek et Lom, 2007 has not yet been determined, but given that all known myxozoan life cycles involve alternation between vertebrate and invertebrate hosts, it has been suggested that terrestrial oligochaetes may be alternate hosts, with trophic transmission between shrews and earthworms (Dyková et al. 2007). However, different dietary preferences of the known host shrew species suggest multiple invertebrate hosts may be present or that direct transmission may occur (Hallett et al. 2015). Ultimately, determination of life cycles of Soricimyxum and transmission routes will provide novel insight into this unique branch of the myxozoan evolutionary tree.

Acknowledgements. The research was supported by the Hungarian Scientific Research Fund (OTKA) projects K100132 and the National Biodiversity Monitoring System. Special thanks are due to Györgyi Ostoros for making the histological sections.

\section{REFERENCES}

Dyková I., Tyml T., Fiala I., Lom J. 2007: New data on Soricimyxum fegati (Myxozoa) including analysis of its phylogenetic position inferred from the SSU rRNA gene sequence. Folia Parasitol. 38 272-276.

Dyková I., Tyml T., Kostкa M. 2011: Xenoma-like formations induced by Soricimyxum fegati (Myxosporea) in three species of shrews (Soricomorpha: Soricidae), including records of new hosts. Folia Parasitol. 58: 249-256.

Hall T.A. 1999: BioEdit: A user-friendly biological sequence alignment editor and analysis program for Windows 95/98/NT. Nucl. Acids Res. 41: 95-98.

Hallett S.L., Atkinson S.D., Bartholomew J.L., Székely C. 2015: Myxozoans exploiting homeotherms. In: B. Okamura, A. Gruhl and J.L. Bartholomew (Eds.), Myxozoan Evolution, Ecology and Development. Springer International Publishing, Cham, pp. $125-135$.

Received 10 December 2015

Accepted 9 May 206
Okamura B., Gruhl, A., Bartholomew J., 2015: Introduction. In: B. Okamura, A. Gruhl and J.L. Bartholomew (Eds.), Myxozoan Evolution, Ecology and Development. Springer International Publishing, Cham, pp. 1-20.

Lom J., Arthur R. 1989: A guideline for the preparation of species descriptions in Myxosporea. J. Fish Dis. 12: 151-156.

Prunescu C.C., Prunescu P., Pucek Z., Lom J. 2007: The first finding of myxosporean development from plasmodia to spores in terrestrial mammals: Soricimyxum fegati gen. et sp. n. (Myxozoa) from Sorex araneus (Soricomorpha). Folia Parasitol. 54: 159-164.

Székely C., Cech G., Atkinson S.D., Molnár K., Egyed L., GubÁNYi A. 2015: A novel myxozoan parasite of terrestrial mammals: description of Soricimyxum minuti sp. n. (Myxosporea) in pygmy shrew Sorex minutus from Hungary. Folia Parasitol. 62: 045 .

Cite this article as: Székely C., Atkinson S.D., Molnár K., Egyed L., Gubányi A., Cech G. 2016: A synopsis of records of myxozoan parasites (Cnidaria: Myxozoa) from shrews, with additional data on Soricimyxum fegati from common shrew Sorex araneus in Hungary and pygmy shrew Sorex minutus in Slovakia. Folia Parasitol. 63: 021. 